\title{
Tobacco and the Health of the Portuguese Elderly: Where to Look?
}

\author{
Pedro Pita Barros
}

\section{Introduction}

Ageing of the Portuguese population is one of the fastest in Europe (European Commission, 2012). The health of an aged population is a concern for policy makers, although estimates in general provide a less dramatic picture than what is usually thought. The health of the elderly and their needs of health care pose challenges to countries that go beyond the expenditure it generates. The Portuguese government, which runs the National Health Service, recognizes that organizational challenges lie ahead. 1

These challenges and the associated health care expenditure are determined also by past life-style decisions of the population. Tobacco consumption is a decision often taken early in life and with life-long implications. Tobacco consumption is seen as a public health issue in many countries, leading to policies aimed at consumption cessation and preventing the start of regular smoking habits in the young generations. As tobacco consumption is associated with respiratory diseases and oncological problems, it is a potentially important determinant of the quality of life and use of health care resources in the elderly population.

Taking advantage of the SHARE database, ${ }^{2}$ we assess the association between smoking habits and health status. The SHARE data include a physical measure of health, respiratory peak flow, as well as the more standard measures of medicaldoctor-diagnosed respiratory problems and self-assessed health. While self-assessed health is widely used, we cannot rule out some bias (people feeling sicker will not smoke, irrespective of whether they are objectively healthier than others or not).

Our results show that tobacco consumption has an important negative impact on the health of the elderly, which is not captured by self-assessed health. From a policy perspective, this is an argument for the routine collection of physical measures of

1 See Barros et al (2011) for a description of the Portuguese health system. See the Portuguese National Health Plan 2012-2016, section 4.2, for a discussion of implications from ageing.

2 http://www.share-project.org. 
health in order to have effective knowledge about the health of the population and for appropriate designs of interventions.

\section{Tobacco consumption and health measures}

We address the association between being (or having been) a regular smoker and the health status. Health status is measured in three different ways: existence of diagnosed respiratory diseases, self-assessed health and respiratory peak flow. This last measure is the maximum value of asking the interviewee to blow into a breath flow meter twice.

Naturally, other factors can, and do, account for differences in health status across the population. We account for variables usually associated with health status: education (measured by years of schooling), income level (measured by adjusted per capita household income), gender, body mass index, living alone, civil status (which may also proxy the presence of informal health care at the household level) and age.

Borges et al (2009) report estimates indicating a high burden of disease associated with smoking in the Portuguese population although no specific treatment of the elderly is done. The authors estimate that $11.7 \%$ of deaths in Portugal are related to smoking, with males taking a higher toll of burden of disease. These estimates are higher than previously reported ones, highlighting the importance of a better knowledge about the relationship between health and smoking habits in the elderly population. Smoking cessation in the Portuguese elderly population is addressed in Fradinho et al (2013). Based on a detailed analysis of the pathways among 28 patients in a single hospital, the authors conclude that smoking-cessation of elderly can be as successful as in younger ages. This suggests that quitting smoking is possible, with potential positive effects in health status. The empirical link of smoking cessation to health is tested later on.

Santos and Barros (2004) take an epidemiological view on smoking habits in the early 2000s in Portugal, showing that the elderly generations smoke less than younger groups. There is, however, no link of smoking habits to health problems addressed in their analysis.

\section{The data source}

This study uses data from SHARE wave 4 release 1.1.1, as of March 28th 2013 (DOI: 10.6103/SHARE.w4.111). The SHARE data collection has been primarily funded by the European Commission through the 5th Framework Program (project QLK6CT-2001-00360 in the thematic program Quality of Life), through the 6th Framework Program (projects SHARE-I3, RII-CT-2006-062193, COMPARE, 
CIT5- CT-2005-028857, and SHARELIFE, CIT4-CT-2006-028812) and through the 7th Framework Program (SHARE-PREP, N ${ }^{\circ}$ 211909, SHARE-LEAP, N ${ }^{\circ}$ 227822 and SHARE M4, $N^{\circ}$ 261982). Additional funding from the U.S. National Institute on Aging (U01 AG09740-13S2, P01 AG005842, P01 AG08291, P30 AG12815, R21 AG025169, Y1-AG-4553-01, IAG BSR06-11 and OGHA 04-064) and the German Ministry of Education and Research as well as from various national sources. The methodological aspects on the SHARE survey are discussed in detail in Börsch-Supan, Brandt, Litwin and Weber (2013), Malter and Börsch-Supan (2013) and Borsch-Supan and Brandt (2013). A paper by Linardakis et al (2013), using SHARE data from earlier waves, which did not include Portugal, computed multiple behavioural risk factors. As expected, it showed that tobacco consumption is an important risk factor.

\section{A first glance at the data}

Our first explorative part is mainly descriptive, reporting the histogram of each proxy of health status versus the status of "never a regular smoker"/ "regular smoker or past regular smoker". We then make a detailed study of the multivariate relationships between tobacco consumption and health status of the 50 years or older in Portugal. A word of caution needs to be given: 'Non-smoker' in the SHARE survey means not having smoked regularly every day for a year. Occasional smokers are classified together with true non-smokers. This definition also means that smokers are a relatively small number of cases in the sample, and should be seen as "strong smokers".

Figures 1-3 do not reveal much difference between the two groups. If any, 'smokers' report better (!) health status. However, this neglects the role of other variables, like age, education, gender, etc. Analysing differences between the groups using t-tests for means, we find that smokers have a lower body mass index and are younger (with an average difference of $-5,6$ years). On average, all other characteristics are not statistically significant across the two groups. ${ }^{3}$

Two issues related to the data deserve some further methodological discussion: The income variable is not asked directly in the SHARE survey. There are several questions related with the households' sources of income in the survey, and the values are obtained by bracketing of intervals. For non-responses, the SHARE team uses an imputation technique. There are several options to do imputation of missing values, and the SHARE data provide five alternatives. We use the first one (the results are not sensitive to whichever income proxy is used).

3 The results from the t-tests are available upon request from the author. 
Table 1. Variables definition

\begin{tabular}{|c|c|}
\hline Name & Description \\
\hline Health & From 1 (bad health) to 5 (excellent health) \\
\hline Peak Respiratory flow (puff) & $\begin{array}{l}\text { Variable reporting the maximum value in the test, } \\
\text { ranging from } 30 \text { (lower limit) to } 890 \text { (upper limit). }\end{array}$ \\
\hline Diagnosed respiratory disease & $\begin{array}{l}\text { Takes value } 1 \text { if a medical doctor diagnosed a } \\
\text { respiratory disease, takes value } 0 \text { otherwise }\end{array}$ \\
\hline Body mass index (bmi) & $\begin{array}{l}\text { Computed as the weight (in kg) divided by the } \\
\text { square of height (in meters) }\end{array}$ \\
\hline Female & $\begin{array}{l}\text { Dummy variable taking value } 1 \text { if female and value } \\
0 \text { if male }\end{array}$ \\
\hline Age & Age in years \\
\hline Income & $\begin{array}{l}\text { Income, in euros, normalized for the size of the } \\
\text { household with a power scale factor of } 0.6\end{array}$ \\
\hline Household size & Number of individuals present in the household \\
\hline Education & Completed schooling years \\
\hline Smoker & $\begin{array}{l}\text { Dummy variable taking value } 1 \text { if a smoker, zero in } \\
\text { all remaining cases }\end{array}$ \\
\hline Quit_smoker & $\begin{array}{l}\text { Dummy variable taking value } 1 \text { if a previous } \\
\text { smoker, zero in all the remaining cases }\end{array}$ \\
\hline Years_smoker & $\begin{array}{l}\text { Number of years of smoker, independently of } \\
\text { current situation (uncompleted spell for current } \\
\text { smokers). }\end{array}$ \\
\hline Live_alone & $\begin{array}{l}\text { Dummy variable taking value } 1 \text { if living alone, zero } \\
\text { otherwise. }\end{array}$ \\
\hline Married & $\begin{array}{l}\text { Dummy variable taking value } 1 \text { if married, } \\
\text { otherwise. }\end{array}$ \\
\hline
\end{tabular}

Source: Own construction, based on original data from SHARE wave 4, release 1.

The second important aspect is whether or not applying weights to each observation. The SHARE data for Portugal included an oversampling in the capital of Lisbon, making the sample diverge from national representativeness. We report econometric results below for both weighted and non-weighted procedures. Table 1 presents the definition of the control variables. 
Figure 1. Self-assessed health, by smoker status

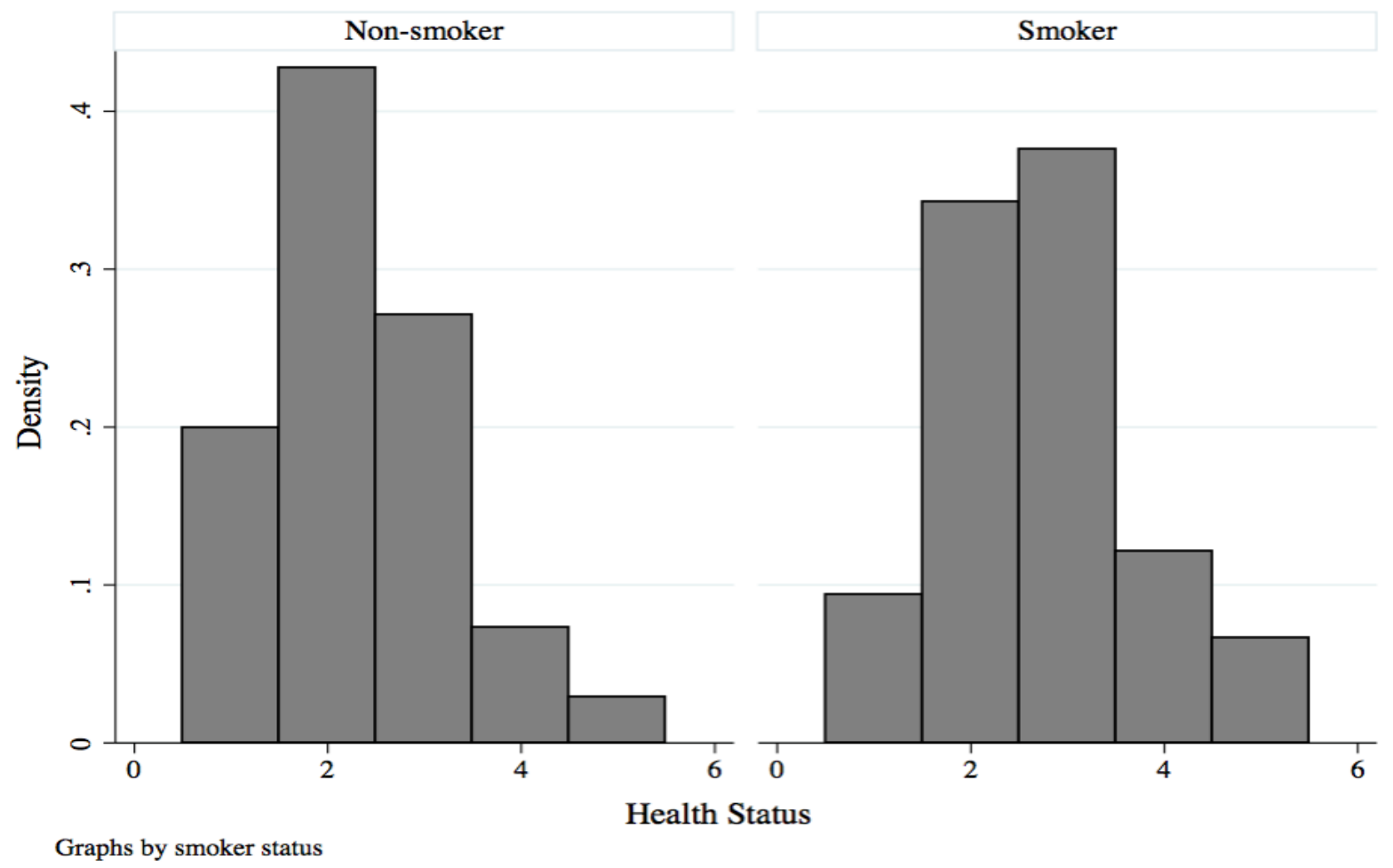

Source: own construction, original data from SHARE wave 4, release 1.

Figure 2. Peak respiratory flow, by smoker status

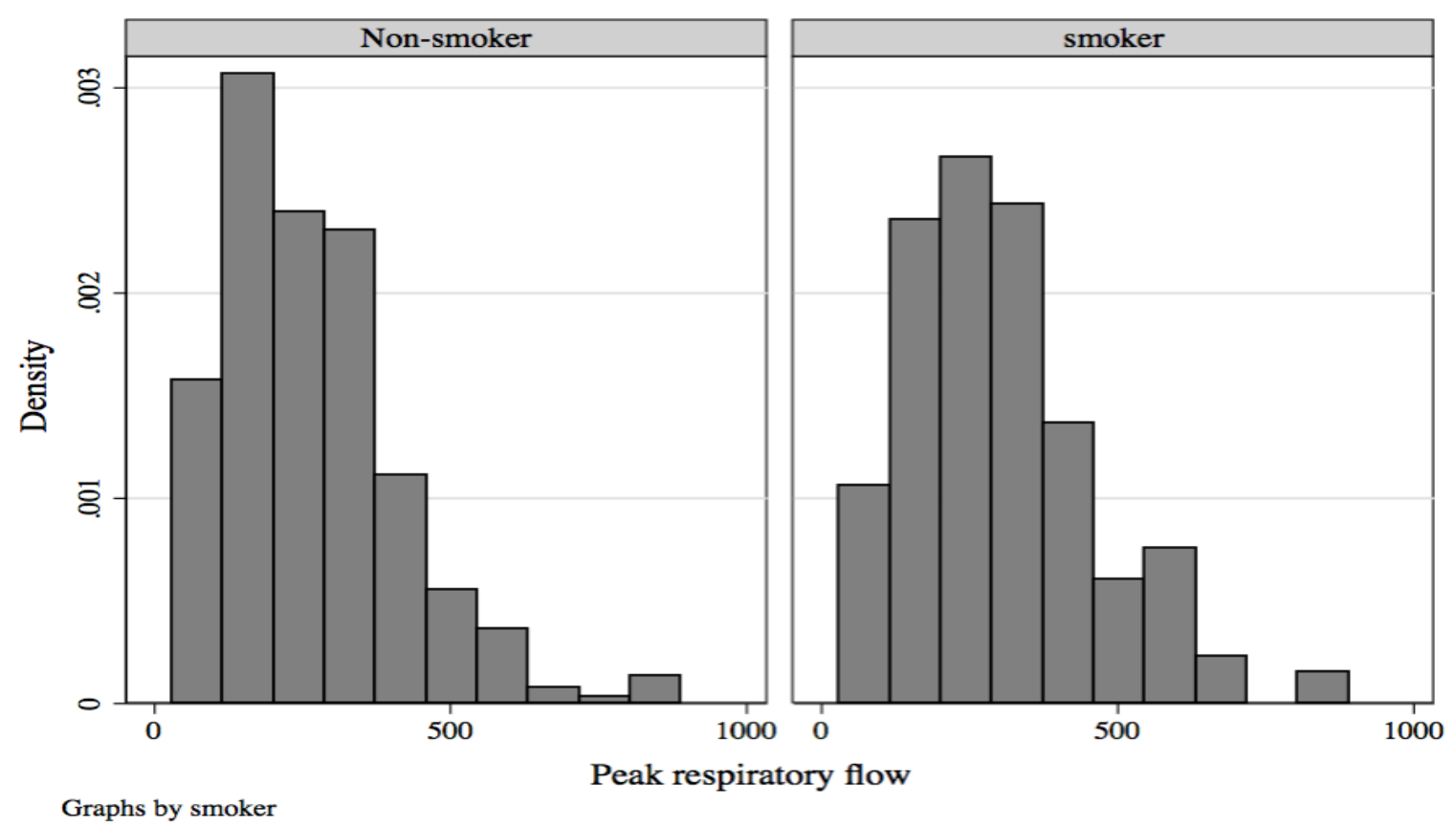

Source: own construction, original data from SHARE wave 4, release 1. 
Figure 3. Diagnosed respiratory disease, by smoker status

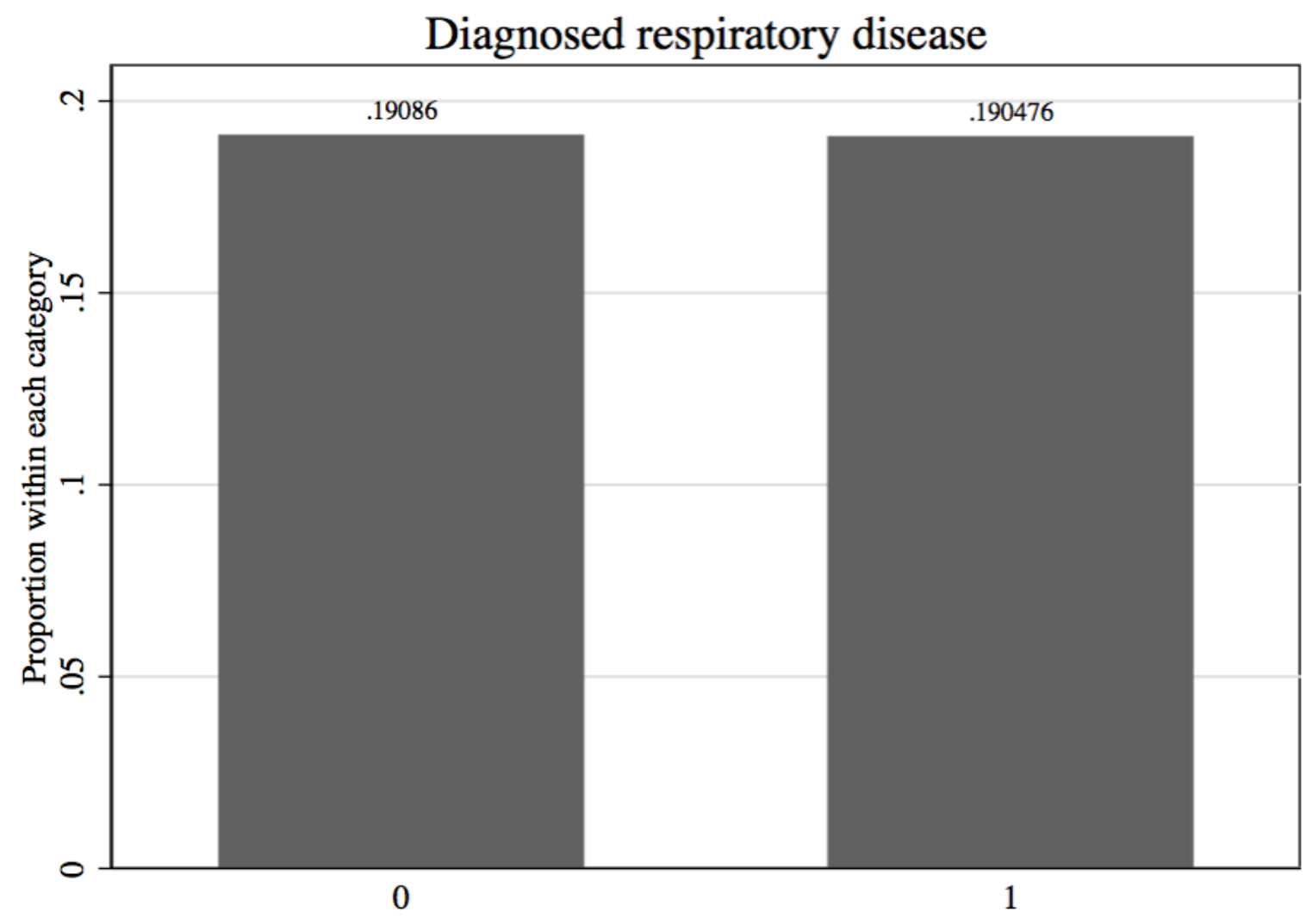

Source: own construction, original data from SHARE wave 4, release 1.

\section{Accounting for multiple simultaneous influences}

The first variable of interest is self-reported health status, which has five ordinal values as possible answers. Dividing the sample according to "never a smoker" / "smoker or ex-smoker", we observe that the latter group has a better self-reported health on average. This may be due to a biased perception of health condition or being a spurious result caused by other relevant effects not accounted for in this crossing.

A more complete analysis is performed using an ordered probit model, which accounts for the ordinal nature of the variable. ${ }^{4}$ Table 2 reports the main estimates.

The results are consistent across variants of the econometric specification. In particular, older ages are associated with lower self-assessed health status. Education, measured by completed schooling years, is positively associated with better health status. Both of these effects are consistent with previous international literature.

On the other hand, there is no association between income and self-assessed health. This is at odds with regular findings of a strong positive income gradient.

4 See Wooldridge (2001) for a description of the econometric procedure and underlying assumptions. 
Still, differences among the Portuguese elderly are more pronounced with respect to education levels than to income levels. Living alone is a factor that contributes to a lower health perception. Taken together, these results are in line with previous literature on the health determinants in Portugal. ${ }^{5}$

Related to obesity, the body mass index variable has a consistent negative association with self-perceived health throughout. A possible non-linear (quadratic) relationship was tested but the results did not reject the hypothesis of a linear relationship.

Having found consistent results with previous works, we turn the attention to the results associated with smoking behaviour, captured by three different variables, as detailed above: being a current smoker, being a previous smoker and number of years as a smoker.

The results from the ordered probit model are clear. Ex-smokers do not self-report a different health status from non-smokers. Smokers do, on the other hand, report a positive direct effect. This suggests that smoking contributes to a better health status if an interpretation of direct causality is assumed, which contradicts many results in the literature. A possible justification for this result is a situation of reversed causality: people with the worst health status and aged above 50 years do not smoke regularly, precisely because of the perception of lower health status. Another, different source with the same perceived bias is that smokers report a better self-assessed health status as part of their internal justification to keep a habit that is often reported as health damaging.

We still have to account for an indirect effect of the years of smoking, which provides some additional information. The computation of the cumulative effect of years of smoking is statistically not different from zero. There is considerably heterogeneity across individuals, as shown in Figure 2.

Therefore, using self-assessed health as the relevant measure, does not help to identify a negative effect of smoking, although we cannot rule out a reverse causality effect associated with health perception and the decision to smoke in the Portuguese population.

5 See, among others, Barros (2009). 
Table 2. Self-assessed health (ordered probit estimation)

\begin{tabular}{|c|c|c|c|c|}
\hline & \multicolumn{2}{|c|}{ Non-weighted estimates } & \multicolumn{2}{|c|}{ Weighted estimates } \\
\hline & $(1)$ & $(2)$ & (3) & $(4)$ \\
\hline body mass index & $\begin{array}{c}-0.039^{* * *} \\
(0.01)\end{array}$ & $\begin{array}{c}-0.039^{* * *} \\
(0.01)\end{array}$ & $\begin{array}{c}-0.049^{* * *} \\
(0.01)\end{array}$ & $\begin{array}{c}-0.051^{* * *} \\
(0.01)\end{array}$ \\
\hline Female & $\begin{array}{c}0.308^{* * *} \\
(0.06)\end{array}$ & $\begin{array}{c}0.304^{* * *} \\
(0.06)\end{array}$ & $\begin{array}{c}0.409^{* *} \\
(0.14)\end{array}$ & $\begin{array}{c}0.365^{* *} \\
(0.12)\end{array}$ \\
\hline Age & $\begin{array}{c}-0.028^{* * *} \\
(0.00)\end{array}$ & $\begin{array}{c}-0.028^{* * *} \\
(0.00)\end{array}$ & $\begin{array}{c}-0.019^{* * *} \\
(0.01)\end{array}$ & $\begin{array}{c}-0.019^{* *} \\
(0.01)\end{array}$ \\
\hline income & $\begin{array}{r}-0.000 \\
(0.00)\end{array}$ & & $\begin{array}{c}-0.000 \\
(0.00)\end{array}$ & \\
\hline household size & $\begin{array}{c}-0.071^{* *} \\
(0.03)\end{array}$ & $\begin{array}{c}-0.070^{* *} \\
(0.02)\end{array}$ & $\begin{array}{c}-0.066 \\
(0.06)\end{array}$ & \\
\hline education & $\begin{array}{c}0.071^{* * *} \\
(0.01)\end{array}$ & $\begin{array}{c}0.069^{* * *} \\
(0.01)\end{array}$ & $\begin{array}{c}0.076^{* * *} \\
(0.02)\end{array}$ & $\begin{array}{c}0.079^{* * *} \\
(0.02)\end{array}$ \\
\hline smoker & $\begin{array}{c}0.329^{*} \\
(0.14)\end{array}$ & $\begin{array}{c}0.349^{* *} \\
(0.11)\end{array}$ & $\begin{array}{l}0.364 \\
(0.35)\end{array}$ & \\
\hline quit_smoker & $\begin{array}{r}-0.015 \\
(0.08)\end{array}$ & & $\begin{array}{r}-0.107 \\
(0.15)\end{array}$ & \\
\hline years_smoker & $\begin{array}{c}-0.009^{* *} \\
(0.00)\end{array}$ & $\begin{array}{c}-0.009^{* * *} \\
(0.00)\end{array}$ & $\begin{array}{c}-0.017^{* *} \\
(0.01)\end{array}$ & $\begin{array}{c}-0.014^{* * *} \\
(0.00)\end{array}$ \\
\hline live_alone & $\begin{array}{l}0.029 \\
(0.13)\end{array}$ & & $\begin{array}{c}-0.519^{*} \\
(0.25)\end{array}$ & $\begin{array}{c}-0.558^{*} \\
(0.22)\end{array}$ \\
\hline married & $\begin{array}{c}0.193^{*} \\
(0.09)\end{array}$ & $\begin{array}{c}0.176^{*} \\
(0.07)\end{array}$ & $\begin{array}{l}0.181 \\
(0.16)\end{array}$ & \\
\hline cut1 & $\begin{array}{c}-3.391^{* * *} \\
(0.35)\end{array}$ & $\begin{array}{c}-3.380^{* * *} \\
(0.34)\end{array}$ & $\begin{array}{c}-3.207^{* * *} \\
(0.64)\end{array}$ & $\begin{array}{c}-3.214^{* * *} \\
(0.66)\end{array}$ \\
\hline cut2 & $\begin{array}{c}-2.076^{* * *} \\
(0.34)\end{array}$ & $\begin{array}{c}-2.066^{* * *} \\
(0.33)\end{array}$ & $\begin{array}{c}-1.981^{* *} \\
(0.65)\end{array}$ & $\begin{array}{c}-2.000^{* *} \\
(0.69)\end{array}$ \\
\hline cut3 & $\begin{array}{c}-0.999^{* *} \\
(0.34)\end{array}$ & $\begin{array}{c}-0.990^{* *} \\
(0.33)\end{array}$ & $\begin{array}{l}-0.971 \\
(0.65)\end{array}$ & $\begin{array}{c}-0.998 \\
(0.69)\end{array}$ \\
\hline cut4 & $\begin{array}{c}-0.324 \\
(0.34)\end{array}$ & $\begin{array}{c}-0.316 \\
(0.32)\end{array}$ & $\begin{array}{l}-0.211 \\
(0.61)\end{array}$ & $\begin{array}{l}-0.252 \\
(0.63)\end{array}$ \\
\hline Observations & 1712 & 1712 & 1652 & 1658 \\
\hline
\end{tabular}

${ }^{*} \mathrm{p}<0.05,{ }^{* *} \mathrm{p}<0.01,{ }^{* * *} \mathrm{p}<0.00$. Standard errors within brackets.

Source: Own construction, original data from SHARE wave 4, release 1.

Notes: First and third columns of results contain full models, second and fourth restrict to statistically significant variables. cut1-cut4 denote the threshold points of the latent variable (Wooldridge, 2001). 
Figure 4. Marginal effect of smoking years on latent variable for self-assessed health

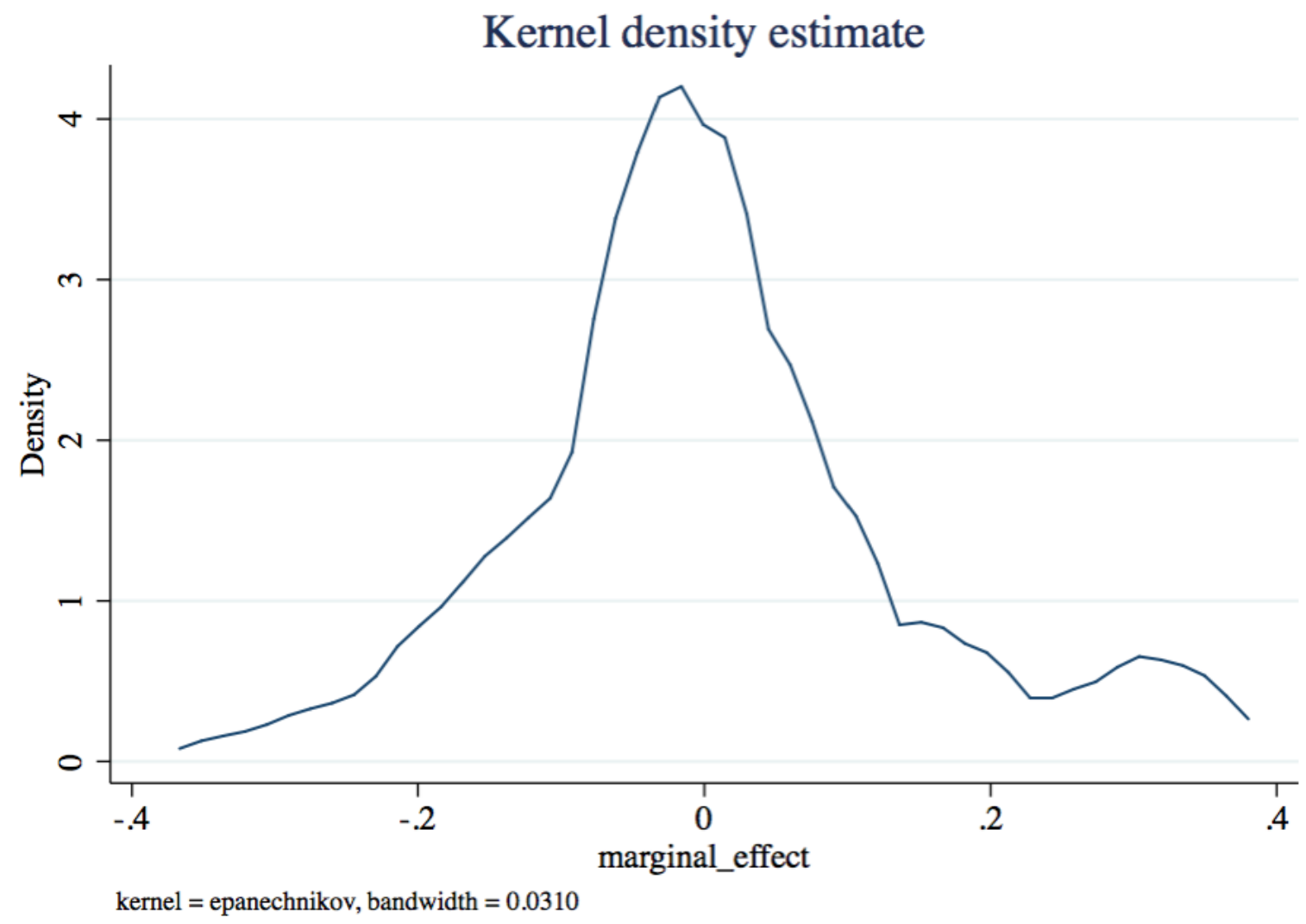

Source: own construction, original data from SHARE wave 4, release 1.

The next step in the analysis is to look at a physical measure of the health status: the peak respiratory flow. Smoking over the years is likely to reduce breathing capabilities, and a lower peak respiratory flow would result.

The peak respiratory flow is collected in the SHARE interviews, and the way it is recorded truncates values lower than a minimum threshold and values above a maximum threshold. This procedure in data collection suggests that a Tobit model is applied, to explicitly account for the characteristics of data collection. ${ }^{6}$ As explanatory factors, the same ones as for the ordered probit model are used (the definitions in Table 1 apply here).

6 The interested reader is again referred to Wooldridge (2001) for details of the econometric procedures. 
Table 3. Peak respiratory flow (Tobit estimation)

\begin{tabular}{|c|c|c|c|c|}
\hline & \multicolumn{2}{|c|}{ Non-weighted estimates } & \multicolumn{2}{|c|}{ Weighted estimates } \\
\hline & (1) & $(2)$ & (3) & (4) \\
\hline body mass index & $\begin{array}{l}0.571 \\
(0.79)\end{array}$ & & $\begin{array}{l}0.597 \\
(1.37)\end{array}$ & \\
\hline Female & $\begin{array}{c}107.308^{* * *} \\
\quad(8.06)\end{array}$ & $\begin{array}{c}108.287^{* * *} \\
(7.86)\end{array}$ & $\begin{array}{c}110.299^{* * *} \\
(12.16)\end{array}$ & $\begin{array}{c}119.294^{* * *} \\
(12.54)\end{array}$ \\
\hline Age & $\begin{array}{c}-3.574^{* * *} \\
(0.42)\end{array}$ & $\begin{array}{c}-3.553^{* * *} \\
(0.38)\end{array}$ & $\begin{array}{c}-3.806^{* * *} \\
(0.88)\end{array}$ & $\begin{array}{c}-4.391^{* * *} \\
(0.82)\end{array}$ \\
\hline income & $\begin{array}{l}0.000 \\
(0.00)\end{array}$ & & $\begin{array}{c}-0.000 \\
(0.00)\end{array}$ & \\
\hline household size & $\begin{array}{c}-1.951 \\
(3.80)\end{array}$ & & $\begin{array}{r}-6.028 \\
(6.70)\end{array}$ & \\
\hline education & $\begin{array}{c}7.397^{* * *} \\
(0.86)\end{array}$ & $\begin{array}{c}7.444^{* * *} \\
(0.84)\end{array}$ & $\begin{array}{c}5.691^{* * *} \\
(1.66)\end{array}$ & \\
\hline smoker & $\begin{array}{c}3.388 \\
(19.72)\end{array}$ & & $\begin{array}{l}21.891 \\
(41.30)\end{array}$ & \\
\hline quit_smoker & $\begin{array}{c}34.659^{* *} \\
(12.02)\end{array}$ & $\begin{array}{c}33.697^{* * *} \\
(9.30)\end{array}$ & $\begin{array}{c}68.696^{* * *} \\
(18.54)\end{array}$ & $\begin{array}{c}58.110^{* * *} \\
(16.56)\end{array}$ \\
\hline years_smoker & $\begin{array}{c}-0.578 \\
(0.43)\end{array}$ & $\begin{array}{c}-0.540^{*} \\
(0.26)\end{array}$ & $\begin{array}{r}-1.620 \\
(0.86)\end{array}$ & $\begin{array}{c}-1.297^{*} \\
(0.55)\end{array}$ \\
\hline live_alone & $\begin{array}{c}5.624 \\
(15.85)\end{array}$ & & $\begin{array}{c}-39.546 \\
(26.35)\end{array}$ & \\
\hline married & $\begin{array}{c}7.825 \\
(12.03)\end{array}$ & & $\begin{array}{c}5.830 \\
(16.73)\end{array}$ & \\
\hline Constant & $\begin{array}{c}383.122^{* * *} \\
(42.72)\end{array}$ & $\begin{array}{c}400.875^{* * *} \\
(25.68)\end{array}$ & $\begin{array}{c}414.001^{* * *} \\
(71.79)\end{array}$ & $\begin{array}{c}472.830^{* * *} \\
(51.36)\end{array}$ \\
\hline Sigma & $\begin{array}{c}134.475^{* * *} \\
(2.48)\end{array}$ & $\begin{array}{c}134.561^{* * *} \\
(2.48)\end{array}$ & $\begin{array}{c}119.021^{* * *} \\
(5.70)\end{array}$ & $\begin{array}{c}121.881^{* * *} \\
(6.19)\end{array}$ \\
\hline Observations & 1523 & 1523 & 1468 & 1468 \\
\hline
\end{tabular}

Source: Own construction, original data from SHARE wave 4, release 1.

Notes: First and third columns of results contain full models, second and fourth restrict to statistically significant variables.

The qualitative results of the control variables are essentially the same as in Table 2, and are presented in Table 3. The same considerations as before apply here. More interesting is to see what happens to the effects of tobacco consumption. For the first variable of interest, "never a smoker" or "being a smoker", no distinction is visible. It should, however, be remembered that 'non-smokers' in this survey is a mix of people that never smoke and the ones classified as occasional smokers. This may blur the inferences from the coefficient of this variable being statistically not different from zero. In contrast to the above results, with self-assessed health as dependent variable, 
the accumulation of smoking years has a clear negative effect on the peak respiratory flow. Smokers have lower peak respiratory flow and the more so the higher the number of years as a smoker. Quitting to smoke, however, has a positive effect on this health-status variable.

Table 4. Presence of diagnosed respiratory disease (probit estimation)

\begin{tabular}{|c|c|c|c|c|}
\hline & \multicolumn{2}{|c|}{ Non-weighted estimates } & \multicolumn{2}{|c|}{ Weighted estimates } \\
\hline & (1) & $(2)$ & (3) & $(4)$ \\
\hline \multirow[t]{2}{*}{ body mass index } & $0.042^{* * *}$ & $0.041^{* * *}$ & $0.038^{*}$ & $0.037^{*}$ \\
\hline & $(0.01)$ & $(0.01)$ & $(0.02)$ & $(0.02)$ \\
\hline \multirow[t]{2}{*}{ female } & $-0.436^{* * *}$ & $-0.432^{* * *}$ & -0.248 & \\
\hline & $(0.09)$ & $(0.09)$ & $(0.22)$ & \\
\hline \multirow[t]{2}{*}{ age } & $0.023^{* * *}$ & $0.022^{* * *}$ & $0.026^{* *}$ & $0.021^{*}$ \\
\hline & $(0.00)$ & $(0.00)$ & $(0.01)$ & $(0.01)$ \\
\hline \multirow[t]{2}{*}{ income } & 0.000 & & 0.000 & \\
\hline & $(0.00)$ & & $(0.00)$ & \\
\hline \multirow[t]{2}{*}{ household size } & $0.086^{*}$ & & 0.131 & \\
\hline & $(0.04)$ & & $(0.07)$ & \\
\hline \multirow[t]{2}{*}{ education } & $-0.036^{* * *}$ & $-0.036^{* * *}$ & $-0.052^{*}$ & $-0.060^{*}$ \\
\hline & $(0.01)$ & $(0.01)$ & $(0.02)$ & $(0.03)$ \\
\hline \multirow[t]{2}{*}{ smoker } & -0.162 & & -0.220 & \\
\hline & $(0.20)$ & & $(0.54)$ & \\
\hline \multirow[t]{2}{*}{ quit_smoker } & -0.025 & & -0.294 & \\
\hline & $(0.13)$ & & $(0.25)$ & \\
\hline \multirow[t]{2}{*}{ years_smoker } & $0.017^{* * *}$ & $0.015^{* * *}$ & $0.026^{* *}$ & $0.018^{* *}$ \\
\hline & $(0.00)$ & $(0.00)$ & $(0.01)$ & $(0.01)$ \\
\hline \multirow[t]{2}{*}{ live_alone } & 0.112 & & $0.869^{* *}$ & $0.620^{*}$ \\
\hline & $(0.15)$ & & $(0.33)$ & $(0.26)$ \\
\hline \multirow[t]{2}{*}{ married } & -0.040 & & 0.143 & \\
\hline & $(0.11)$ & & $(0.24)$ & \\
\hline \multirow[t]{2}{*}{ Constant } & $-3.541^{* * *}$ & $-3.254^{* * *}$ & $-4.057^{* * *}$ & $-3.285^{* * *}$ \\
\hline & $(0.44)$ & $(0.37)$ & $(0.85)$ & $(0.76)$ \\
\hline Observations & 1716 & 1716 & 1656 & 1656 \\
\hline
\end{tabular}

Source: Own construction, original data from SHARE wave 4, release 1.

Notes: First and third columns of results contain full models, second and fourth restrict to statistically significant variables.

A third proxy for health status, is the presence or not of a respiratory disease, diagnosed by a medical doctor. As the dependent variable in this case takes only 
values 0 (not having a respiratory disease) and 1 (having a respiratory disease), a simple probit model is adequate. ${ }^{7}$

The estimates are reported in Table 4. Once again, the socio-economic characteristics effects are consistent with previous tables of results. Note that for previous dependent variables, higher value meant a better health status, while under this third proxy for health status a higher value - having a respiratory disease - means a lower health status. The signs of the coefficients will be reversed in comparison with the ones above.

Briefly, and focussing the attention on the smoking-habit-related variables, years of smoking are statistically significant determinants the presence of a respiratory disease. This holds true whether the individual is currently a smoker or an ex-smoker. The cumulative number of smoking years is the crucial point.

\section{Final Remarks}

There is a growing consensus that sustainability of modern health systems will, to a considerable extent, have to rely on healthier habits by the population. Ageing of the population is also posing new challenges to the organization of health systems. One of the more important habits is the decision to smoke - it has an impact on health according to the medical literature and it is a decision that can be changed. The elderly are often considered to belong to a vulnerable population and in increasing need of health care. While age is not reversible, the decision to smoke is a controllable risk factor.

Gaining knowledge about the effects on health of smoking habits in the older ages of the population is thus of great interest to public health. However, there is a need for caution in the way we measure these effects. Relying on the common self-assessed health information can be misleading, as the decision to smoke (or not quitting) is likely to be influenced by the perception people have about their own health and /or the perception of health itself may rationalize implicitly the decision to keep on smoking at advanced ages.

The use of two other proxies for the health status shows clearly the relevance of this consideration. The peak respiratory flow and the presence of a respiratory disease diagnosed by a medical doctor indicate a detrimental effect of tobacco consumption to the health of the population above 50 years old in Portugal. The number of years as a smoker does have a sizeable effect, part of it remaining even after the individual quits smoking.

Besides smoking, for this population above 50 years old, the standard effects of more advanced age (negative) and higher education level (positive) versus health

$7 \quad$ See Wooldridge (2001). 
status were observed, whilst income had no discernible effect. Living alone has a negative association with health status, consistent with the view that it is a risk factor for the health of the elderly in Portugal.

Pedro Pita Barros is Professor of Economics at Universidade Nova de Lisboa. He is Research Fellow of CEPR (London), President of the European Association of Health Economics, head of the Nova Healthcare Initiative - Research Knowledge Center (Nova School of Business and Economics), member of the EC Expert Panel on Effective Ways of Investing in Health and member of the board of Institute of Public Policy Thomas Jefferson - Correia da Serra. 


\section{References}

Barros, Pedro Pita, Economia da Saúde - Conceitos e Comportamentos. Princípia. 2nd edition. Lisboa, 2009.

Barros, Pedro Pita, Sara Ribeirinho Machado and Jorge Simões, Portugal: Health system review. Health Systems in Transition, 2011, 13(4):1-156. Available at http://goo.gl/F0edYo.

Borges, Margarida, Miguel Gouveia, João Costa, Luís dos Santos Pinheiro, Sérgio Paulo, António Vaz Carneiro, "The burden of disease attributable to smoking in Portugal," Revista Portuguesa de Pneumologia Vol. XV N.o 6 Nov/Dez 2009.

Börsch-Supan A., M. Brandt, H. Litwin and G. Weber (Eds). Active ageing and solidarity between generations in Europe: First results from SHARE after the economic crisis. Berlin: De Gruyter. 2013.

Borsch-Supan, A., Brandt, M., Hunkler, C., Kneip, T., Korbmacher, J., Malter, F., Schaan, B., Stuck, S., Zuber, S., "Data Resource Profile: The Survey of Health, Ageing and Retirement in Europe (SHARE)." International Journal of Epidemiology, 2013. DOI: 10.1093/ije/dyt088.

European Commission, The 2012 Ageing Report - Economic and budgetary projections for the EU27 Member States (2010-2060), Joint Report prepared by the European Commission (DG ECFIN) and the Economic Policy Committee (AWG). 2012.

Fradinho, Marta, Cristina Matos and Fernando Nogueira, "Success of smoking cessation in the elderly: A challenge, abstract of presentation in European Respiratory Society Annual Congress 2013”, European Respiratory Journal, 42 (Suppl 57) 3341. 2013.

Linardakis, Manolis, Emmanouil Smpokos, Angeliki Papadaki, Ioannis D. Komninos, Nikos Tzanakis, and Anastas Philalithis, "Prevalence of multiple behavioral risk factors for chronic diseases in adults aged $50+$, from eleven European countries - the SHARE study (2004)," Preventive Medicine, 57: (2013), 168-172.

Malter, F., Börsch-Supan, A. (Eds.). SHARE Wave 4: Innovations \& Methodology. Munich: MEA, Max Planck Institute for Social Law and Social Policy. 2013.

National Health Plan 2012 - 2016, Section 4.2 - Goal for the health system Promoting Supportive Environments for Health throughout the Life Cycle, 2012, available at http://goo.gl/ff5s2v.

Santos, Ana Cristina and Henrique Barros, "Smoking patterns in a community sample of Portuguese adults, 1999-2000," Preventive Medicine 38: (2004), 114119.

Wooldridge, Jeffrey, Econometric analysis of cross section and panel data. MIT Press. Cambridge, 2001. 


\section{Appendix}

The different dependent variables used have distinct missing values, which lead to slightly different samples in each estimation procedure. For completeness, we report below the descriptive statistics associated with each particular set of estimates.

Table A1. Dependent variable: self-assessed health status

\begin{tabular}{llllll}
\hline Variable & Obs & Mean & Std. Dev. & Min & Max \\
\hline health & 1652 & 2.330508 & .9762604 & 1 & 5 \\
bmi & 1652 & 27.15543 & 4.4641 & 15.20381 & 54.01026 \\
female & 1652 & .4485472 & .4974962 & 0 & 1 \\
age & 1652 & 65.25182 & 9.442268 & 51 & 95 \\
income & 1652 & 17392.67 & 24774.66 & 620.7382 & 210000 \\
hhsize & 1652 & 2.447337 & 1.091906 & 1 & 8 \\
education & 1652 & 6.12046 & 4.230419 & 0 & 24 \\
smoker & 1652 & .1016949 & .3023382 & 0 & 1 \\
quit_smoker & 1652 & .2306295 & .4213633 & 0 & 1 \\
years_smoker & 1652 & 8.383172 & 15.4071 & 0 & 73 \\
live_alone & 1652 & .12046 & .3255973 & 0 & 1 \\
married & 1652 & .7953995 & .4035315 & 0 & 1 \\
\hline
\end{tabular}

Source: Own construction, original data from SHARE wave 4, release 1.

Table A2. Dependent variable: peak respiratory flow

\begin{tabular}{llllll}
\hline Variable & Obs & Mean & Std. Dev. & Min & Max \\
\hline puff & 1468 & 271.5783 & 151.4236 & 30 & 890 \\
bmi & 1468 & 27.1869 & 4.410767 & 15.20381 & 54.01026 \\
female & 1468 & .4543597 & .4980823 & 0 & 1 \\
age & 1468 & 64.54973 & 8.960238 & 51 & 95 \\
income & 1468 & 17430.09 & 24815.87 & 620.7382 & 210000 \\
hhsize & 1468 & 2.446185 & 1.071013 & 1 & 8 \\
education & 1468 & 6.232289 & 4.269531 & 0 & 24 \\
smoker & 1468 & .1042234 & .3056543 & 0 & 1 \\
quit_smoker & 1468 & .229564 & .4206958 & 0 & 1 \\
years_smoker & 1468 & 8.331063 & 15.21075 & 0 & 70 \\
live_alone & 1468 & .1158038 & .3200986 & 0 & 1 \\
married & 1468 & .8085831 & .3935505 & 0 & 1 \\
\hline
\end{tabular}

Source: Own construction, original data from SHARE wave 4, release 1. 
Table A3. Dependent variable: presence of diagnosed respiratory disease

\begin{tabular}{llllll}
\hline Variable & Obs & Mean & Std. Dev. & Min & Max \\
\hline resp_disease & 1656 & .1908213 & .3930672 & 0 & 1 \\
bmi & 1656 & 27.15126 & 4.462015 & 15.20381 & 54.01026 \\
female & 1656 & .4486715 & .4975086 & 0 & 1 \\
age & 1656 & 65.25423 & 9.436318 & 51 & 95 \\
income & 1656 & 17389.82 & 24752.04 & 620.7382 & 210000 \\
hhsize & 1656 & 2.44686 & 1.090836 & 1 & 8 \\
education & 1656 & 6.128019 & 4.233435 & 0 & 24 \\
smoker & 1656 & .1014493 & .3020139 & 0 & 1 \\
quit_smoker & 1656 & .2300725 & .4210061 & 0 & 1 \\
years_smoker & 1656 & 8.362923 & 15.39398 & 0 & 73 \\
live_alone & 1656 & .1201691 & .3252574 & 0 & 1 \\
married & 1656 & .7958937 & .4031688 & 0 & 1 \\
\hline
\end{tabular}

Source: Own construction, original data from SHARE wave 4, release 1. 